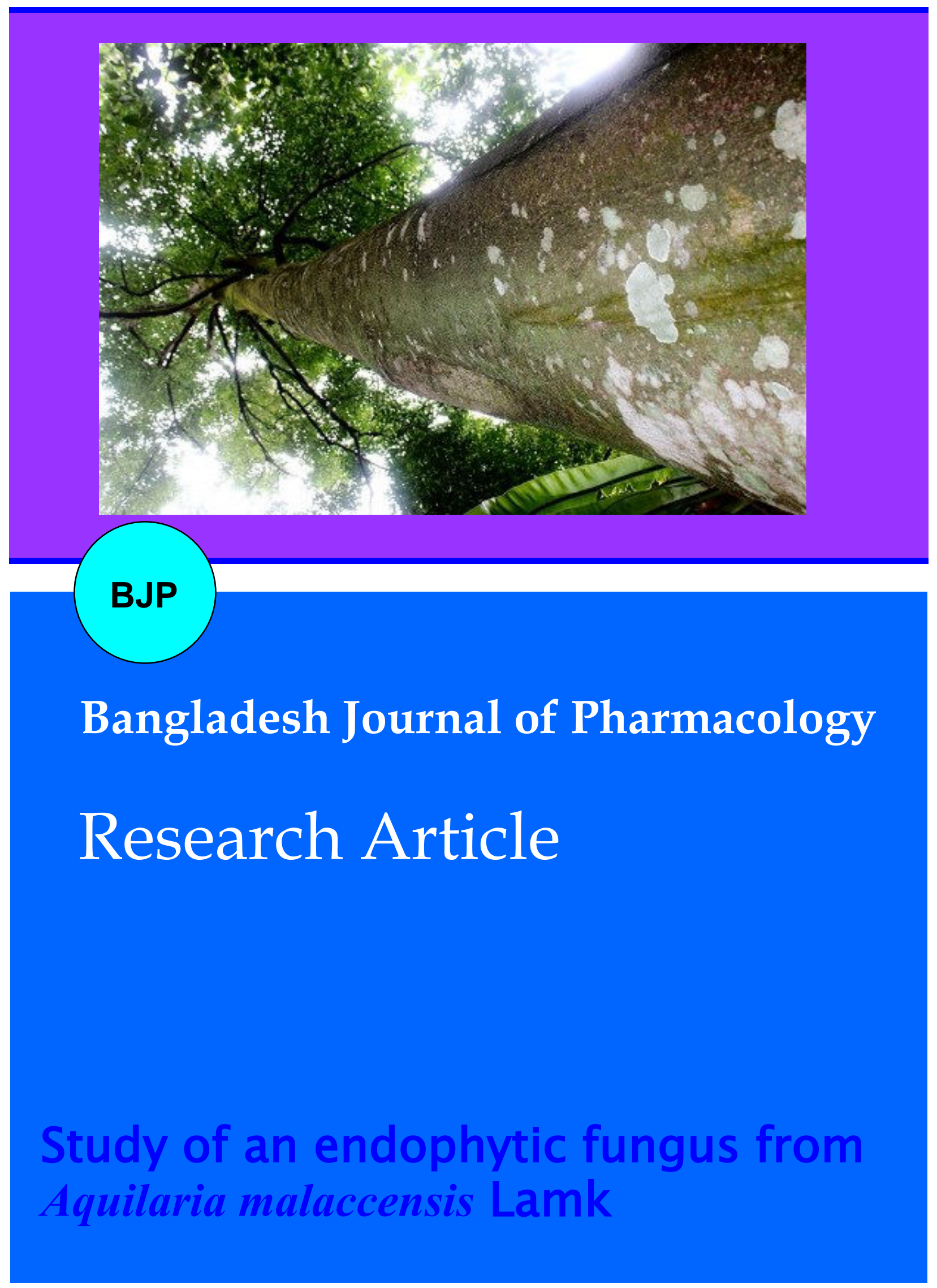


Abstracted/indexed in Academic Search Complete, Agroforestry Abstracts, Asia Journals Online, Bangladesh Journals Online, Biological Abstracts, BIOSIS Previews, CAB Abstracts, Current Abstracts, Directory of Open Access Journals, EMBASE/Excerpta Medica, Google Scholar, HINARI (WHO), International Pharmaceutical Abstracts, Open J-gate, Science Citation Index Expanded and Social Sciences Citation Index

\title{
Study of an endophytic fungus from Aquilaria malaccensis Lamk
}

\author{
Mohammad Shoeb, Shahanara Begum and Nilufar Nahar
}

Department of Chemistry, University of Dhaka, Dhaka 1000, Bangladesh.

\begin{tabular}{|c|c|}
\hline \multicolumn{2}{|l|}{ Article Info } \\
\hline Received: & 30 March 2010 \\
\hline Accepted: & 22 April 2010 \\
\hline Available Online: & 5 May 2010 \\
\hline \multicolumn{2}{|c|}{ DOI: $10.3329 /$ bjp.v5i1.4687 } \\
\hline \multicolumn{2}{|c|}{$\begin{array}{l}\text { Cite this article: } \\
\text { Shoeb M, Begum S, Nahar N. Study of } \\
\text { an endophytic fungus from Aquilaria } \\
\text { malaccensis Lamk. Bangladesh J Phar- } \\
\text { macol. 2010; 5: 21-24 }\end{array}$} \\
\hline
\end{tabular}

\begin{abstract}
Nine endophytic fungal strains labeled as AL-1, AL-2, AS-1, AS-2, AS-3, AS-4, AR-1, AR-2 and AR-4 were isolated from the medicinal plant Aquilaria malaccensis Lamk. Three compounds 1,7-dihydroxy-3-methoxyanthraquinone, propyl p-methoxy phenyl ether and 6-methoxy-7-0-(p-methoxyphenyl)coumarin were isolated from the ethyl acetate extract of the strain AL-2 by silica gel column chromatography and HPLC. The structures of isolated compounds were elucidated by spectroscopic techniques i.e. UV, IR, 1D and 2D NMR. Extracts of the strain AL-2 were assessed for antibacterial activities against Gram positive and Gram negative bacteria and general toxicity against brine shrimp lethality assay. The ethyl acetate extract showed only mild activity against two Gram positive bacteria (Bacillus cereus and Staphylococcus aureus).
\end{abstract}

\section{Introduction}

Natural products, derived from microorganisms and plants, have been used for the treatment of various diseases and a large number of modern drugs have been developed from them. The word endophyte means in the plant and refers to all microorganisms that live in the intercellular spaces of stems, petioles, roots and leaves of plants causing no apparent symptoms of disease (Petrini, 1991). Endophytic fungi spend the whole or parts of its life cycle colonizing inter or intracellularly inside the healthy tissues of the host plant. Some species of endophytic fungi have been identified as sources of anticancer, antidiabetic, insecticidal, immunosuppressive and biocontrol compounds. A large number of secondary metabolites have been isolated and characterized from endophytic fungi since the discovery of endophytes in Daren, Germany in 1904 (Strobel et al., 2004). The discovery of penicillin from Penicillium notatum inspired scientists to work with fungi. Cryptocandin, isolated from Cryptosporiopsis quercina, are currently being considered for use against a number of fungal diseases of the skin and nails
(Strobel et al., 2004; Strobel et al., 1999). Taxol, an anticancer agents, was originally isolated from the bark of the Pacifica Yew tree Taxus brevifolia (Wani et al., 1971). Later, it was discovered that fungi (Taxomyces andreanae and Pestalotiopsis microspora) associated with this yew tree also produce taxol (Strobel et al., 1996). As part of our ongoing research on endophytc fungi of Bangladeshi medicinal plants several secondary metabolites were isolated from different endophytes. Aquilaria malaccensis Lamk (locally known as Agor) is one of the medicinal plants of Bangladesh. In this paper, we report the isolation of endophytic fungi from A. malaccensis and study of the fungal strain AL-2 for chemical and biological properties.

\section{Materials and Methods}

\section{Instrument}

UV and IR spectra were recorded on Shimadzu UV 160A and Shimadzu IR-470 spectrometer, respectively. The ${ }^{1} \mathrm{H}$ and ${ }^{13} \mathrm{C}$ NMR spectra were recorded on a Bruker $400 \mathrm{MHz}$ spectrometer using tetramethylsilane (TMS) 
as the internal reference. High performance liquid chromatography (HPLC) separation was performed on reversed phased C-18 (25 cm x $4.6 \mathrm{~mm}, 5 \mathrm{pm}$, injection volume: $100 \mathrm{pL}$ ) column using Shimadzu Class $10 \mathrm{VP}$ with UV-Visible detector at wavelength $254 \mathrm{~nm}$. Media was prepared under Laminar flow (Thermo Forma. Class 11 A1; Biological safety cabinet). Media was sterilized using Hirayama autoclave (Hirayama MFG Corp.).

\section{Plant collection and sterilization}

The medicinal plant Aquilaria malaccensis Lamk (locally known as Agor) was collected from Sylhet. Different parts of the plant were cut into small pieces. Each plant part was surface sterilized with $70 \%$ ethanol, 3\% sodium hypochlorite and sterile water (Schulz et al., 1993). The agar media was autoclaved at $120^{\circ} \mathrm{C}$ at 1 atmosphere pressure for $30 \mathrm{~min}$.

\section{Isolation of endophytic fungi}

The surface sterilized different part of plant materials i.e. leaves, stems and roots were inoculated on autoclaved potato-carrot agar media on a sterilized petri dish (90 $\mathrm{mm}$ in diameter) and after 21 days, twenty one fungal strains were isolated for identification. By dereplication of common fungi, nine strains labeled as AL-1, AL-2, AS-1, AS-2, AS-3, AS-4, AR-1, AR-2 and AR-4 were found to have optimum growth for further cultivation. The fungal strain AL-2 was selected for chemical and biological studies.

\section{Culture extraction}

The fungal strain AL-2 was fermented in a large scale (400 petri dishes of $90 \mathrm{~mm}$ diameter) in the potatocarrot agar semi solid medium at $\sim 22-25^{\circ} \mathrm{C}$. After 21 days the fungi were collected in a round bottom flask and the content was then subjected to freeze-drying. The dried powdered material was extracted with ethyl acetate $(3 \times 1,500 \mathrm{~mL}$ for 24 hours, at room temperature). The ethyl acetate extract was evaporated to dryness and $250 \mathrm{mg}$ extract was obtained. A small part of the extract ( $20 \mathrm{mg}$ ) was saved for anti-bacterial and brine shrimp lethality assays. The rest of the extract was used to isolate pure compounds.

\section{Antibacterial activity assay}

The antibacterial activity of ethyl acetate extract of the strain AL-2 was performed against two Gram positive bacteria i.e. Bacillus cereus, Staphylococcus aureus and five Gram negative bacteria i.e. Escherichia coli 0157, Salmonella typhi, Shigella boydii, Pseudomonas aeruginosa and Vibrio cholerae by disk diffusion assay (Atta-urRahman et al., 1999).

The specific concentration of the extract was $12 \mathrm{mg} / \mathrm{mL}$. Sterile filter paper disc of $6 \mathrm{~mm}$ in diameter were loaded with 200 pg/ disc using micropipette and was dried under laminar airflow hood. Standard antibiotic, Kanamycin (30 pg/ disc) was used as a positive control. The loaded discs were placed in petri dish $(90 \mathrm{~mm}$ in diameter) containing sterile nutrient agar medium seeded with test microorganisms using sterile transfer loop for antibacterial screening. The plates were kept at $4^{\circ} \mathrm{C}$ for 12 hours. Then the plates were kept in an incubator at $37^{\circ} \mathrm{C}$ for $12-18$ hours. The antibacterial activities of the test agent were determined by measuring the diameter of the zone of inhibition in $\mathrm{mm}$. Zone of inhibition ranging from $7-9 \mathrm{~mm}$ was considered insignificant and zone of inhibition 10-12 mm, 13-15 $\mathrm{mm}$ and above $15 \mathrm{~mm}$ were considered as mild, moderate and significant activity, respectively.

\section{Brine shrimp lethality Assay}

The ethyl acetate extract of the strain AL-2 was tested against brine shrimp lethality assay for general toxicity using different concentration of the extracts and following the protocol proposed by Meyer (Meyer et al., 1982). By counting the number of brine shrimps died after 24 hours and after 48 hours the LD50 value for the parent ethyl acetate extract was calculated manually.

\section{Chemical studies of the extract}

The extract (200 mg) was dissolved in chloroform and silica gel (400 mg) was added to it. A column was packed with silica gel using hexane as column equilibrating solvent. After application of the sample, solvents of increasing polarities from $100 \%$ hexane to dichloromethane (DCM) and finally 50\% methanol with dichloromethane were used for elution. The fractions were collected in test tubes and on the basis of their $R_{f}$ values on TLC, sixteen fractions were obtained. Among them one fraction gave single spot in TLC and collected as pure compound I (4.0 mg) after washing with $n$ hexane. One of the fractions S-16 (20 mg) gave three spots with tailing in TLC $(6 \%$ methanol in dichloromethane) and was purified by HPLC using mobile phase methanol and water (40:60). Finally, two compounds II $(3.5 \mathrm{mg})$ and III $(3.5 \mathrm{mg})$ were isolated by HPLC from S-16.

\section{Properties of the isolated compounds}

Compound I: Yellow colored and gummy (4.0 mg), UV (in DCM): Kx 262, 274 and $415 \mathrm{~nm}$. IR (KBr pellet): Vmax 2900, 2850, 1720, 1450 and $1250 \mathrm{~cm}^{-1}$. !H NMR (CDCb, TMS as standard): 7.8 (d, J=7.1 Hz, 2H), 7.7 (d, $\mathrm{J}=7.1 \mathrm{~Hz}, 2 \mathrm{H}), 7.5$ (s), 7.1 (s), 7.0 (s), 3.9 (s), 12.1 (bs) ppm.

Compound II: Light yellow colored and solid (3.5 mg), UV (in DCM): Kax 228, $278 \mathrm{~nm}$. IR (KBr pellet): Vmax 1512, 1457, $1075 \mathrm{~cm}^{-1}$. aH NMR (CDCb, TMS as standard): $7.5(\mathrm{~d}, \mathrm{~J}=8.4 \mathrm{~Hz}, 2 \mathrm{H}), 6.6(\mathrm{~d}, \mathrm{~J}=8.4 \mathrm{~Hz}, 2 \mathrm{H})$, $4.8(\mathrm{~d}, \mathrm{~J}=6.8 \mathrm{~Hz}, 2 \mathrm{H}), 4.6(\mathrm{~d}, \mathrm{~J}=6.9 \mathrm{~Hz}, 2 \mathrm{H}), 3.7(\mathrm{~s}), 3.7(\mathrm{t}$, $\mathrm{J}=7.2 \mathrm{~Hz}), 1.3(\mathrm{~m}), 1.0(\mathrm{t}, \mathrm{J}=7.2 \mathrm{~Hz})$ ppm. 


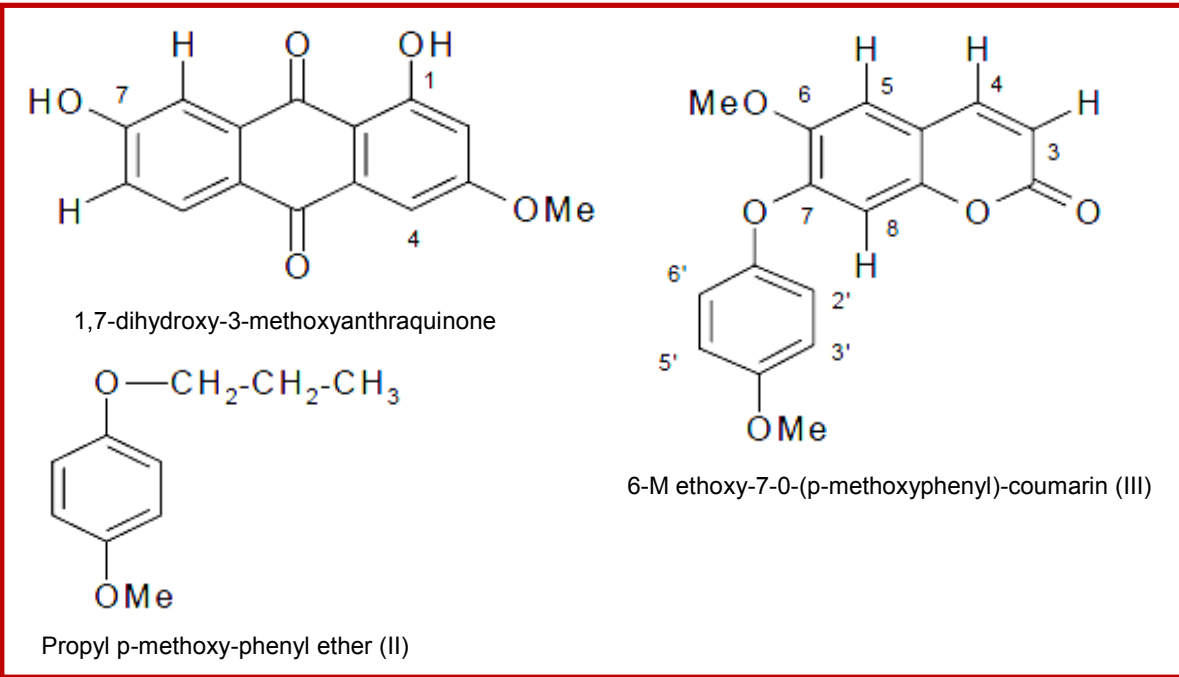

Figure 1: isolated from the ethyl acetate extract of the strain AL-2 by silica gel column chromatography and HPLC

Compound III: Off-white and solid (3.5 mg), UV (DCM): Kax 230, 260, 295, $345 \mathrm{~nm}$. IR (KBr pellet): Vmax 1720, 1512, $1490 \mathrm{~cm}^{-1}$. !H NMR (CDCb, TMS as standard): 7.6 (d, J=9.0 Hz), $7.3(\mathrm{~d}, \mathrm{~J}=7.4 \mathrm{~Hz}), 7.1$ (s), 7.0 $(\mathrm{d}, \mathrm{J}=7.4), 6.6(\mathrm{~s}) 6.1(\mathrm{~d}, \mathrm{~J}=9.0), 3.8(\mathrm{~s}), 3.6$ (s) ppm.

\section{Results and Discussion}

Nine endophytic fungal strains labeled as AL-1, AL-2, AS-1, AS-2, AS-3, AS-4, AR-1, AR-2 and AR-4 were isolated from A. malaccensis. Three compounds I, II and III were isolated from the ethyl acetate extract of the strain AL-2 by silica gel column chromatography. The NMR spectrum of I gave five signals in the aromatic

\section{Table I}

Zone of inhibition of ethyl acetate extract of AL-2

\begin{tabular}{|lcc|}
\hline Name of organisms & \multicolumn{2}{c|}{ Zone of inhibitiona } \\
\cline { 2 - 3 } & $\begin{array}{c}\text { Kanamycin } \\
(30 \mathrm{pg} / \\
\text { disc })\end{array}$ & $\begin{array}{c}\text { Ethyl acetate } \\
\text { extract } \\
(200 \mathrm{pg} / \text { disc })\end{array}$ \\
\hline $\begin{array}{l}\text { Gram-positive bacteria } \\
\text { Bacillus cereus }\end{array}$ & 36 & 12 \\
Staphylococcus aureus & 40 & 10 \\
Gram-negative bacteria & & \\
Escherichia coli 0157 & 37 & 0 \\
Shigella boydii & 39 & 0 \\
Pseudomonas aerugi-nosa & 42 & 0 \\
Salmonella typhi & 40 & 0 \\
Vibrio cholerae & 35 & 9 \\
a7-9 mm: insignificant, 10-12 mm: mild activity, 13-15 mm: moder- \\
ate activity, above 15 mm: significant
\end{tabular}

region. Two doublets at $7.8 \mathrm{~J}=7.1 \mathrm{~Hz}$ ) and $7.7 \mathrm{ppm} \mathrm{J}=7.1$ $\mathrm{Hz}$ ) indicated two aromatic protons in o-position coupling each other. Other three singlets in the aromatic region at 7.5, 7.1, 7.0 ppm indicated that they do not have any neighboring hydrogen. One sharp signal at 3.9 ppm was assigned for oxygenated methyl proton. The chemical shift at $12.11 \mathrm{ppm}$ was due to the chelation of H-bonding of hydroxyl group and carbonyl -oxygen of aromatic system (Aly et al., 2008). The ${ }^{1} \mathrm{H}$ NMR data of I was similar to macrosporin, a substituted anthraquinone, reported from an endophytic fungus of Ampelomyces sp. isolated from the medicinal plant Urospermum picroides. The compound I showed UV absorbance at 262, 274 and $415 \mathrm{~nm}$. The UV absorption fitted very well with reported values (264, 274 and $416 \mathrm{~nm}$ ) of anthraquinone isolated from other sources (Aly et al., 2008; Debbab et al., 2009). From JH NMR and UV absorbance, the structure of I was confirmed as 1,7-dihydroxy-3-methoxyanthraquinone (Figure 1). The IR spectrum of II showed absorbances at 1512, 1457 and $1075 \mathrm{~cm}^{-1}$ due to the presence of aromatic moiety and ether group. In a $\mathrm{H}$ NMR spectrum of II two most downfield signals at $7.5\left(\mathrm{~J}=8.4 \mathrm{~Hz},{ }^{2} \mathrm{H}\right)$ and $6.6 \mathrm{ppm} \mathrm{J}=8.4 \mathrm{~Hz}, 2 \mathrm{H}$ ) indicated the presence of four aromatic protons. Two sets of doublet at $4.8 \mathrm{ppm}$ $\mathrm{J}=6.8 \mathrm{~Hz}, \mathrm{H}$ ) and $4.6 \mathrm{ppm} \mathrm{J}=6.9 \mathrm{~Hz}, \mathrm{H}$ ) were accounted for two protons of oxygenated methylene group. A sharp singlet $(3 \mathrm{H})$ at 3.7 ppm was for an oxymethyl group. Triplet at 3.7 was due to two protons attached of oxygenated methylene group. Chemical shift at 1.0 and $1.3 \mathrm{ppm}$ were due to methyl proton and methylene proton, respectively. In the $\mathrm{a}-\mathrm{H}-\mathrm{H}$ COSY spectrum strong crossed peak between 6.6 and 7.5 ppm indicated that they coupled with each other.

Another correlation was also observed between 1.0 ppm with 1.3 ppm. Combining IR, aH-, aH-aH COSY 
spectral data, II was determined as propyl pmethoxy phenyl ether.

The UV spectrum (in methanol) of III showed absorption bands at 230, 260, 295 and $345 \mathrm{~nm}$ which suggested the presence of coumarin skeleton (Kwak et al, 2001). In the IR spectrum, absorbances were observed at 1720, 1512 and $1490 \mathrm{~cm}^{-1}$ indicating the presence of coumarin skeleton. In the $\mathrm{aH}$ NMR spectrum, two doublets at $7.6(\mathrm{~J}=9.0 \mathrm{~Hz})$ and $6.1(\mathrm{~J}=9.0 \mathrm{~Hz})$ ppm were due to two aromatic protons. Two singlets at 7.1 and $6.6 \mathrm{ppm}$ were also for two aromatic protons without having any neighboring hydrogen. The ${ }^{1} \mathrm{H}$ NMR spectrum also showed two doublets at $7.3 \mathrm{ppm}$ $(\mathrm{J}=7.4 \mathrm{~Hz})$ and $7.0 \mathrm{ppm} \mathrm{J}=7.4 \mathrm{~Hz})$. Strong correlation between chemical shift at $7.3 \mathrm{ppm}$ and chemical shift at $7.0 \mathrm{ppm}$ in the ${ }^{1} \mathrm{H}-{ }^{1} \mathrm{H}$ COSY spectrum indicated that they were p-substituted aromatic protons. Two sharp singlets at $3.8(3 \mathrm{H})$ and $3.6(3 \mathrm{H})$ were due to two oxymethyl groups attached to aromatic moiety. The ${ }^{1} \mathrm{H}$ NMR signals of III was indicative of a coumarin nucleus (Kwak et al., 2001). Combining spectroscopic data i.e. UV, IR, ${ }^{1} \mathrm{H}$ NMR and $1 \mathrm{H}-1 \mathrm{H}$ COSY, the structure of III was elucidated as 6- methoxy-7-0-(pmethoxyphenyl)-coumarin.

The antibacterial activity of ethyl acetate extract of AL-2 was performed against two Gram positive bacteria i.e. Bacillus cereus, Staphylococcus aureus and five Gram negative bacteria i.e. Escherichia coli 0157, Salmonella typhi, Shigella boydii, Pseudomonas aeruginosa and Vibrio cholerae. The extract showed mild activity against two Gram positive bacteria i.e. Bacillus cereus and Staphylococcus aureus (Table I). The ethyl acetate extract of AL-2 was also tested for general toxicity against brine shrimp lethality assay and was found low activities. Further study is necessary to determine the relationship between the endophyte and host plants.

\section{Acknowledgement}

The authors are grateful to International Foundation for Sciences, Sweden and International Program in the Chemical Sciences, Uppsala, Sweden for financial supports. Shahanara is grateful to BOSE Center for Advanced Studies and Natural Sciences, University of Dhaka for research fellowship.

\section{References}

Aly AH, Edrada-Ebel RA, Wray V, Muller WEG, Kozytska S, Hentschel U, Proksch P, Ebel R. Bioactive metabolites from the endophytic fungus Ampelomyces sp. isolated from the medicinal plant Urospermum picroides. Phytochemistry 2008; 69: 1716-25.

Atta-ur-Rahman, Choudhary MI, Thomsen WJ. Bioassay techniques for drug development. Harwood Academic Publishers, 1999, pp 16-17.

Debbab A, Aly AH, Edrada-Ebel RA, Wray V, Muller WEG, Totzke F, Zirrgiebel U, Schachtele C, Kubbutat MHG, Lin WH, Mosaddak M, Hakiki A, Proksch P, Ebel R. Bioactive metabolites from endophytic fungus Stemphylium globuliferum isolated from Mentha pulegium. J Nat Prod. 2009; 72: 626-31.

Kwak JH, Lee KB, Schmitz, FJ. Four new coumarin derivatives from Artemisia keiskeana. J Nat Prod. 2001; 64: 1081-83.

Meyer BN, Ferrigni RN, Putnam JE, Jacobsen LB, Nichols DE, Mclaughlin JL. Brine shrimp: A convenient general bioassay for active plants constituents. Planta Med. 1982; 45: 31-34.

Petrini O. Fungal endophytes of tree leaves. In: Microbial ecology of leaves. New York, Springer-Verlag, 1991, p 179.

Schulz B, Wanke U, Drager S, Aust HJ. Endophytes from herbaceous plants and shrubs: Effectiveness of surface sterilization methods. Mycological Res. 1993; 97: 1447-50.

Strobel G, Yang X, Sears J, Kramer R, Sidhu RS, Hess WM. Taxol from Pestalotiopsis microspora, and endophytic fungus of Taxus wallachiana. Microbiology 1996; 142: 435-40.

Strobel GA, Miller RV, Miller C, Condron M, Teplow DB, Hess WM. Cryptocandin, a potent antimycotic from the endophytic fungus Cryptosporiopsis cf. quercina. Microbiology. 1999; 145: 1919-26.

Strobel G, Daisy B, Castillo U, Harper J. Natural products from engophytic microorganisms. J Nat Prod. 2004; 67: 257-68.

Wani MC, Taylor HL, Wall ME, Coggon P, Mcphail AT. J Am Chem Soc. 1971; 93: 2325-27. 